\title{
Retraction Note to: Correlation of air pollutants and prediction of physical fitness index based on wireless sensor network
}

\author{
Na Ping ${ }^{1} \cdot$ Pengfei Sun ${ }^{2} \cdot$ Qian Kang ${ }^{2}$
}

Published online: 10 November 2021

(c) Saudi Society for Geosciences 2021

Retraction Note to: Arabian Journal of Geosciences (2021) 14: 1885 https://doi.org/10.1007/s12517-021-08178-w

The Editor-in-Chief and the Publisher have retracted this article because the content of this article is nonsensical. The peer review process was not carried out in accordance with the Publisher's peer review policy. Authors Qian Kang and $\mathrm{Na}$ Ping have not responded to correspondence regarding this retraction. The Publisher has not been able to obtain a current email address for author Pengfei Sun.

Publisher's note Springer Nature remains neutral with regard to jurisdictional claims in published maps and institutional affiliations.

The original article can be found online at https://doi.org/10.1007/ s12517-021-08178-w.

Qian Kang

na2021cg@163.com

1 Shijiazhuang University, Shijiazhuang 050000, Hebei, China

2 Hebei University of Chinese Medicine, Shijiazhuang 050000, Hebei, China 